\title{
EFEITOS DA ESTIMULAÇÃO ELÉTRICA NEUROMUSCULAR SOBRE O MEMBRO POSTERIOR IMOBILIZADO DE RATOS DURANTE 15 DIAS: ANÁLISES METABÓLICAS E MORFOMÉTRICAS
}

\author{
Durigan JlQ ${ }^{1,2}$, Cancelliero KM ${ }^{1,2}$, Dias $\mathrm{CKN}^{1,2}$, Silva CA ${ }^{2}$, Guirro RRJ ${ }^{2}$ e Polacow MLO ${ }^{2}$ \\ ${ }^{1}$ Universidade Federal de São Carlos, São Carlos, SP - Brasil \\ ${ }^{2}$ Universidade Metodista de Piracicaba, Piracicaba, SP - Brasil \\ Correspondência para: Karina Maria Cancelliero, Rua Gomes Carneiro, 875, Centro, CEP 13400-530, Piracicaba, SP - \\ Brasil, e-mail: joao_durigan@hotmail.com ou karca@terra.com.br
}

Recebido: 08/08/2005 - Aceito: 28/03/2006

\begin{abstract}
RESUMO
Objetivo: Avaliar o efeito da estimulação elétrica (EE) sobre o perfil metabólico e morfométrico dos músculos do membro posterior de ratos submetidos à imobilização durante 15 dias. Método: Ratos Wistar foram divididos em 3 grupos ( $\mathrm{n}=5$ ): controle, imobilizado por 15 dias e imobilizado associado à EE por 15 dias. Foram avaliados: reserva de glicogênio (RG) dos músculos sóleo (S), extensor longo dos dedos (ELD), gastrocnêmio branco (GB), gastrocnêmio vermelho (GV) e tibial anterior (TA), além do peso do sóleo, área das fibras e tecido conjuntivo do S. A análise estatística foi feita pelos testes ANOVA e Kruskal-Wallis (p<0,05). Resultados: A imobilização promoveu alterações significativas ( $p<0,05)$ como: redução nas RG (S: 44,73\%, GB: 47,82\%, GV: 46,34\%, ELD: $41,66 \%$, TA: $48,38 \%)$, no peso $(7,2 \%)$ e na área das fibras (35\%) do S, além do aumento da densidade do tecido conjuntivo (160\%). A EE promoveu aumento significativo $(\mathrm{p}<0,05)$ nas RG de todos os músculos imobilizados (S: 90,47\%, GB: 62,5\%, GV: 95,45\%, ELD: $76,19 \%$, TA: $56,25 \%)$, no peso (20,94\%) e na área das fibras (19,65\%) do S e também promoveu redução significativa $(15,38 \%, p<0,05)$ na densidade do tecido conjuntivo. Conclusões: A EE minimizou a redução das RG, preveniu a redução da área das fibras e a proliferação do tecido conjuntivo nos músculos submetidos à imobilização.
\end{abstract}

Palavras-chave: estimulação elétrica, imobilização, morfometria, metabolismo, fisioterapia.

\section{ABSTRACT \\ Effects of Neuromuscular Electrical Stimulation on Rat Hind Limbs Immobilized for 15 Days: Metabolic and Morphometric Analyses}

Objective: To evaluate the effect of electrical stimulation on the metabolic and morphometric profile of rat hind limb muscles subjected to immobilization for 15 days. Method: Wistar rats were divided into three groups $(\mathrm{n}=5)$ : control; immobilized for 15 days; and immobilized for 15 days with electrical stimulation. The glycogen reserves of the soleus, extensor digitorum longus (EDL), white gastrocnemius (WG), red gastrocnemius (RG) and tibialis anterior (TA) muscles were evaluated, along with the weight, fibrous area and conjunctive tissue of the soleus. The statistical analysis was performed using the Anova and Kruskal-Wallis tests $(\mathrm{p}<0.05)$. Results: Immobilization promoted significant alterations $(\mathrm{p}<0.05)$, such as: reductions in the glycogen reserves (soleus: $44.73 \%$, WG: $47.82 \%$, RG: 46.34\%, EDL: 41.66\%, TA: 48.38\%) and in the weight (7.2\%) and fibrous area (35\%) of the soleus, and also increased connective tissue density $(160 \%)$. Electrical stimulation promoted a significant increase $(\mathrm{p}<0.05)$ in the glycogen reserves of all the immobilized muscles: (soleus: $90.47 \%$, WG: $62.5 \%$, RG: 95.45\%, EDL: 76.19\%, TA: 56.25\%) and in the weight $(20.94 \%)$ and fibrous area $(19.65 \%)$ of the soleus, and also promoted a significant reduction $(15.38 \%, \mathrm{p}<0.05)$ in connective tissue density. Conclusion: Electrical stimulation minimized the reduction in glycogen reserves and prevented the reduction in fibrous area and proliferation of connective tissue in the muscles subjected to immobilization.

Key words: electrical stimulation, immobilization, morphometry, metabolism, physical therapy. 


\section{INTRODUÇÃO}

A hipotrofia muscular ocorre como conseqüência da desnervação, lesões musculoesqueléticas, imobilização articular, repouso prolongado, tratamento por glicocorticóide, septicemia, câncer e até mesmo pelo envelhecimento ${ }^{1}$.

Desse modo, o desuso muscular promove redução na área das fibras musculares, bem como na densidade dos capilares $^{2,3}$. Simultaneamente, ocorre proliferação do tecido conjuntivo intramuscular tanto no perimísio quanto no endomísio, além de aumento do "turnover" do colágeno no tecido $^{4,5,6}$.

A homeostasia metabólica das fibras musculares também pode ser comprometida, induzindo o quadro de resistência à insulina e a um estado catabólico nos musculoesqueléticos afetados de humanos ${ }^{7,8}$. Porém, ainda não está claro como o desuso muscular crônico ou a imobilização alteram a sinalização de insulina9 .

É importante salientar que os estudos de imobilização apresentam caráter multifatorial diferindo quanto ao modelo e material utilizado para promover o desuso, tempo da imobilização, posição articular, atividade eletromiográfica e tipagem das fibras musculares analisada, e isso, conseqüentemente, determina os resultados ${ }^{10}$.

Segundo Qin et al. ${ }^{11}$ a atrofia por desuso varia de $15 \%$ a $70 \%$, dependendo dos animais utilizados e das fibras avaliadas. Alguns autores sugerem que a maioria das mudanças ocorre nos primeiros sete dias ${ }^{5,6,12}$. Porém, outros trabalhos demonstram atrofia significativa no período de 14 dias em diferentes modelos de desuso muscular ${ }^{1,13}$.

No intuito de minimizar os eventos desencadeados pelo desuso muscular, diversas técnicas têm sido utilizadas, buscando melhorar as condições homeostáticas das fibras musculares, com destaque para estimulação elétrica neuromuscular $(\mathrm{EE})^{14}$.

Nesse contexto, foram estudados os efeitos da EE sobre a morfologia e reservas de glicogênio e a densidade de área das fibras por 15 dias em músculo sóleo denervado e foi observada redução da densidade de área do tecido conjuntivo, apontando para possível redução da fibrose, e aumento na quantidade de grânulos de glicogênio ${ }^{15}$.

A EE também promove a elevação na atividade contrátil das fibras musculares, desse modo a dinâmica de captação e metabolismo da glicose e a atividade das vias metabólicas celulares são aumentadas, uma vez que os grupos submetidos somente à $\mathrm{EE}$ apresentaram maiores reservas de glicogênio ${ }^{16}$.

Partindo dessas observações, o objetivo desse trabalho foi avaliar o efeito da EE sobre o perfil metabólico e morfométrico dos músculos do membro posterior de ratos submetidos à imobilização por órtese de resina acrílica durante 15 dias.

\section{MATERIAL E MÉTODOS}

Ratos Wistar (3 a 4 meses, 250-300g) foram mantidos em condições controladas de biotério, recebendo água e ração ad libitum e tratados segundo recomendações do Guide for Care Use of Laboratory Animals (National Research Council, 1996). A caixa, contendo 3 animais, tinha a dimensão de $40 \times 30 \mathrm{~cm}$ e foi forrada com jornal, já que a serragem poderia entrar no compartimento interno da órtese, podendo provocar lesões cutâneas.

Os animais foram divididos em 3 grupos $(\mathrm{n}=5)$ : controle (C), imobilizado durante 15 dias (I) com órtese de resina acrílica $^{17}$, e imobilizado associado à EE durante 15 dias (IEE). Após anestesia com pentobarbital sódico (40 mg/Kg peso), o membro posterior esquerdo foi tricotomizado e a EE foi realizada em sessão diária de 20 minutos, por um período de 15 dias, iniciando 24 horas após a imobilização. Um eletrodo foi colocado na região inguinal e o outro no músculo tríceps sural, sendo que no membro imobilizado este segundo eletrodo foi acoplado dentro da órtese. Os parâmetros da estimulação elétrica foram: freqüência de $10 \mathrm{~Hz}, \mathrm{~T}=0,4 \mathrm{~ms}$, pulso quadrático bifásico. A intensidade da corrente foi padronizada em $5.0 \mathrm{~mA}$, a partir da visualização da contração muscular, sendo acrescida de $1.0 \mathrm{~mA}$ a cada 5 minutos, com intuito de manter o nível de contração durante todo o período de estimulação. Os eletrodos de silicone-carbono apresentavam área de $1 \mathrm{~cm}^{2}$ cada.

Após o período experimental, as análises realizadas foram: conteúdo de glicogênio segundo proposta de Siu et al. ${ }^{18}$, dos músculos sóleo (S), extensor longo dos dedos (ELD), gastrocnêmio branco (GB), gastrocnêmio vermelho $(\mathrm{GV})$ e tibial anterior (TA), além do peso, área das fibras e densidade do tecido conjuntivo do músculo sóleo.

Para a análise morfométrica do sóleo o segmento ventral foi fixado em solução tamponada de formol a $10 \%$ e o material foi processado em parafina obtendo-se vários cortes transversais não seriados de $7 \mu \mathrm{m}$ de espessura, que foram corados pela Hematoxilina-Eosina (HE).

Foi utilizado um sistema de análise de imagens constituído de um software Image Pró-plus 4.0 (Media Cybernects), câmera digital (JVC) acoplada a um microscópio (Zeiss) com integração a um microcomputador. Todas as imagens foram captadas com objetiva de 10x.

Foram analisadas as áreas de 375 fibras do músculo sóleo por animal, assim escolhidos: 15 fibras por área, sendo 5 áreas por corte, num total de 5 cortes por animal. Utilizouse de um retículo quadriculado para a escolha de 15 fibras por corte, aleatoriamente, que coincidiam com as interseções de retas.

Para a análise da densidade do tecido conjuntivo intramuscular foi utilizado o sistema de planimetria por contagem de pontos ${ }^{19}$, e a quantificação foi realizada por meio de um retículo com quadrados de $2500 \mu \mathrm{m}^{2}$ contendo 56 
intersecções de reta. Foram contados os pontos coincidentes no endomísio e perimísio, em 5 áreas por corte, sendo 5 cortes por animal, perfazendo um total de 1400 pontos por animal.

A área relativa do tecido conjuntivo (densidade de área) foi calculada dividindo-se a soma do número de pontos coincidentes nas intersecções de reta sobre o tecido conjuntivo (endomísio e perimísio) pelo número total de pontos.

A análise estatística foi realizada inicialmente pelo teste de normalidade Kolmogorov-Smirnov. Para as variáveis peso muscular e glicogênio, que apresentaram distribuição normal, foi utilizado a ANOVA seguido do teste de Tukey. Para as variáveis áreas das fibras musculares e densidade do tecido conjuntivo foi utilizado o teste de Kruskal-Wallis, já que as mesmas não apresentaram distribuição normal. Em todos os cálculos foi fixado um nível crítico de $5 \%(\mathrm{p}<0,05)$.

\section{RESULTADOS}

As reservas de glicogênio dos músculos do membro inferior submetidos à imobilização durante 15 dias, apresentaram redução significativa $(p<0,05)$ em todos os músculos analisados: no $\mathrm{S}(44,73 \%), \mathrm{GB}(47,82 \%), \mathrm{GV}$ $(46,34 \%)$, ELD $(41,66 \%)$ e no TA $(48,38 \%)$, conforme mostra a tabela 1 . Vale destacar que, a imobilização também

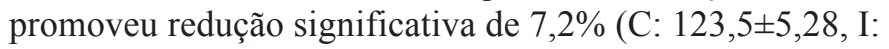
$114,6 \pm 6,42, \mathrm{p}<0,05)$ do peso muscular do sóleo .

Quanto à análise morfométrica, a imobilização promoveu redução significativa $(\mathrm{p}<0,05)$ da área das fibras do músculo sóleo em 35\% (tabela 2, figura 1-B), bem como aumento significativo $(\mathrm{p}<0,05)$ da densidade do tecido conjuntivo intramuscular em 160\% em relação ao grupo controle, conforme mostra a tabela 3 (figura 1-B).

A EE promoveu aumento significativo $(p<0,05)$ nas reservas de glicogênio em todos os músculos imobilizados analisados: $90,47 \%$ no $\mathrm{S}, 62,5 \%$ no $\mathrm{GB}, 95,45 \%$ no $\mathrm{GV}$, $76,19 \%$ no ELD e de $56,25 \%$ no TA, conforme mostra a tabela 1 .

Com relação ao peso do músculo sóleo, a EE promoveu aumento significativo de 20,94\% (I: $114,6 \pm 6,42$, IEE: $138,6 \pm 6,42, \mathrm{p}<0,05)$ se comparado ao grupo imobilizado. A análise das fibras do músculo sóleo mostrou que o recurso promoveu aumento significativo de $19,65 \%(\mathrm{p}<0,05)$, se comparado ao grupo imobilizado (tabela 2, figura 1-C). A EE também promoveu redução de forma significativa na ordem de $15,38 \%(\mathrm{p}<0,05)$ da densidade do tecido conjuntivo se comparado com o grupo imobilizado (tabela 3, figura 1-C).

\section{DISCUSSÃO}

Clinicamente, a imobilização articular pode promover efeitos deletérios no sistema musculoesquelético, como redução da elasticidade muscular, redução da amplitude de movimento e até mesmo a contratura muscular devido à proliferação do tecido conjuntivo ${ }^{20}$. Além dessas alterações, sabe-se também que o desuso pode levar a hipotrofia muscular, redução das reservas de glicogênio, creatina quinase, dos sarcômeros em série, da força e resistência à fadiga ${ }^{8}$.

Tem sido observado que as fibras musculares lentas (tipo I) possuem maior vulnerabilidade à atrofia do que as fibras das fibras musculares rápidas (tipo II), devido a diferenças no seu metabolismo ${ }^{21}$. Nesse contexto, foi observado que as enzimas oxidativas respondem por meio da diminuição da sua atividade durante a imobilização, sugerindo que as fibras musculares que possuem metabolismo predominantemente oxidativo (tipo I), foram as mais susceptíveis à atrofia muscular $^{22}$.

Além da susceptibilidade à atrofia inerente ao metabolismo das fibras tipo I, outro fator que determina essa condição são as características de fibras posturais. Nesse sentido, Ploug et al. ${ }^{23}$ relacionaram a maior susceptibilidade do sóleo à atrofia por inatividade devido ser um músculo postural e assim possuir uma atividade basal maior do que os não posturais.

Esses estudos corroboram a afirmação de Lieber, reforçando o que a literatura relata, de que os músculos considerados antigravitacionários, os uniarticulares e os que possuem maior proporção de fibras lentas são os mais vulneráveis à atrofia induzida pelo desuso muscular ${ }^{24}$. Sendo assim, o músculo sóleo, predominantemente composto por fibras do tipo I, foi o escolhido para a análise morfométrica devido a sua maior susceptibilidade à atrofia inerente ao desuso.

A imobilização durante 15 dias em posição neutra, conseguiu promover, no músculo sóleo, redução significativa

Tabela 1. Média \pm dpm da concentração de glicogênio (mg/100mg) do músculo sóleo (S), gastrocnêmio branco (GB), gastrocnêmio vermelho (GV), extensor longo dos dedos (ELD) e tibial anterior (TA) dos grupos controle (C), imobilizado por 15 dias (I) e imobilizado associado à estimulação elétrica neuromuscular por 15 dias (IEE), $\mathrm{n}=5$. * comparado ao $\mathrm{C}$, \#comparado ao grupo I, $\mathrm{p}<0,05$.

\begin{tabular}{cccccc}
\hline & S & GB & GV & ELD & TA \\
\hline C & $0,38 \pm 0,09$ & $0,46 \pm 0,06$ & $0,41 \pm 0,04$ & $0,36 \pm 0,08$ & $0,31 \pm 0,09$ \\
I & $0,21 \pm 0,05^{*}$ & $0,24 \pm 0,01^{*}$ & $0,22 \pm 0,04^{*}$ & $0,21 \pm 0,07^{*}$ & $0,16 \pm 0,03 *$ \\
IEE & $0,40 \pm 0,03 \#$ & $0,39 \pm 0,12 \#$ & $0,43 \pm 0,11 \#$ & $0,37 \pm 0,11 \#$ & $0,25 \pm 0,05 \#$ \\
\hline
\end{tabular}


Tabela 2. Mediana da área das fibras $\left(\mu \mathrm{m}^{2}\right)$ do músculo sóleo nos grupos controle $(\mathrm{C})$, imobilizado por 15 dias (I) e imobilizado associado à estimulação elétrica neuromuscular por 15 dias (IEE), $n=5$. *omparado ao C, \# comparado ao grupo I, $\mathrm{p}<0,05$.

\begin{tabular}{cccc}
\hline Grupos & $\mathbf{1}^{\mathbf{0}}$ Quartil & Mediana & $3^{\mathbf{0}}$ Quartil \\
\hline C & 2180,23 & 2496,13 & 2878,66 \\
I & 1335,483 & $1624,03 *$ & 1876,434 \\
IEE & 1561,401 & $1943,21^{*} \#$ & 2386,532
\end{tabular}

Tabela 3. Mediana da densidade de área (\%) do tecido conjuntivo dos grupos controle (C), imobilizado por 15 dias (I), e imobilizado associado à estimulação elétrica neuromuscular por 15 dias (IEE), $\mathrm{n}=5$. * comparado ao C, \# comparado ao grupo I, $\mathrm{p}<0,05$.

\begin{tabular}{cccc}
\hline Grupos & $\mathbf{1}^{\mathbf{0}}$ Quartil & Mediana & $\mathbf{3}^{\mathbf{0}}$ Quartil \\
\hline $\mathbf{C}$ & 7,14 & 8,93 & 10,71 \\
$\mathbf{I}$ & 16,07 & $23,21 *$ & 28,57 \\
IEE & 14,29 & $19,64 * \#$ & 25,00 \\
\hline
\end{tabular}

de $7,2 \%$ do peso, $35 \%$ da área das fibras, aumento de $160 \%$ do tecido conjuntivo, além de redução das reservas de glicogênio de todos os músculos analisados, mostrando a inter-relação da atividade contrátil com a homeostasia energética e a morfologia da fibra muscular, apontando para o quadro de hipotrofia muscular.

Segundo Qin et al. ${ }^{11}$ a imobilização por diferentes períodos resulta em atrofia variando de $15 \%$ a $70 \%$, dependendo dos animais utilizados e das fibras avaliadas. Gomes et al. ${ }^{3}$, observaram redução de $43 \%$ da área da fibra do músculo sóleo imobilizado durante 3 semanas. Kannus et al. ${ }^{2}$ relataram redução de $69 \%$ da área das fibras desse músculo imobilizado por meio de aparelho gessado durante 3 semanas.

Bodine et al. ${ }^{1}$ compararam o peso do músculo gastrocnêmio de ratos em 3 modelos de desuso, a imobilização, suspensão e desnervação. Os autores observaram que após 14 dias de desuso, ocorreu redução de aproximadamente 50\% do peso muscular nos animais submetidos à desnervação, $45 \%$ nos imobilizados e $30 \%$ nos ratos submetidos à suspensão.

Com relação à densidade do tecido conjuntivo, a imobilização promoveu aumento significativo de $279 \%$. Esses

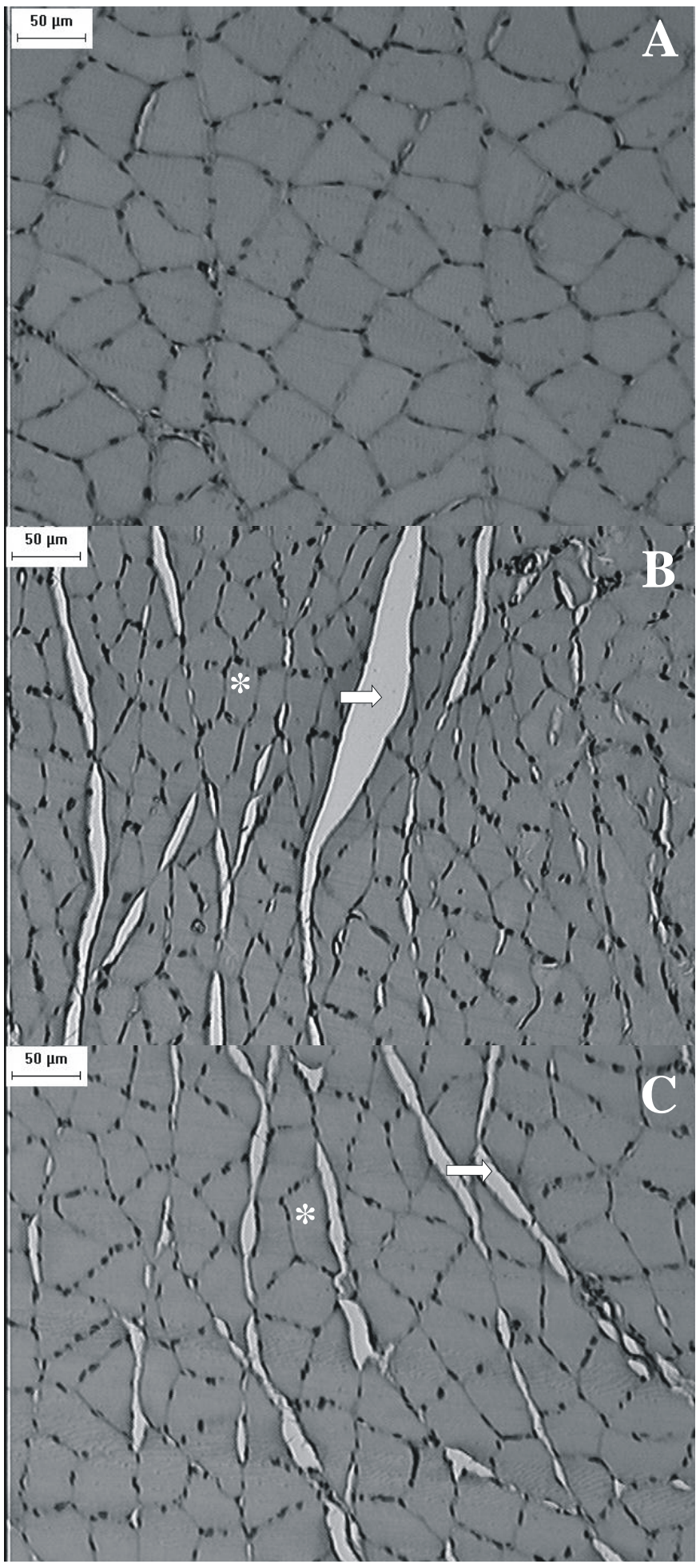

Figura 1. A - Fibras do músculo sóleo do grupo C. B - Músculo sóleo imobilizado, observar a redução da área das fibras (asterisco) e o aumento do tecido conjuntivo (seta) em relação ao grupo C. C - Músculo sóleo imobilizado e tratado com EE 15 dias, observar o aumento da área das fibras (asterisco) e redução do tecido conjuntivo (seta) em relação ao grupo I. 
resultados estão de acordo com a literatura, já que para Józsa et al. ${ }^{20}$, independente do modelo de desuso muscular estudado (imobilização, tenotomia ou desnervação), a quantidade de tecido conjuntivo intramuscular aumenta significativamente, variando de $50 \%$ a $700 \%$.

Williams e Goldspink observaram que, em apenas 2 dias de imobilização na posição encurtada, o músculo sóleo apresentou aumento do tecido conjuntivo no perimísio, sendo que foi mais pronunciado no $14^{\mathrm{o}} \mathrm{dia}^{5}$. Okita et al. ${ }^{6}$ observaram que em 2 semanas de desuso ocorreu proliferação do tecido conjuntivo, desarranjo das fibras de colágeno no endomísio, redução do comprimento dos sarcômeros, bem como da amplitude articular no músculo sóleo de ratos imobilizado em posição encurtada de tornozelo.

Amiel et al. ${ }^{4}$ observaram alterações no metabolismo de colágeno nos tecidos conjuntivos densos imobilizados decorrentes da falta de forças fisiológicas atuando sobre ele, o que impede a formação de ligações cruzadas, dando origem a fibras imaturas, as quais são responsáveis pela fibrose. Também foi relatado aumento do "turnover" do colágeno no tecido conjuntivo nesta situação ${ }^{2,5}$.

O desuso muscular provocado por condições de períodos longos no leito, colocação de órteses ou fixações em membros e microgravidades induzem resistência à insulina e a um estado catabólico nos musculoesqueléticos afetados de humanos ${ }^{7}$. Esse quadro de resistência à insulina pode explicar a redução das reservas de glicogênio inerente à imobilização em todos os músculos analisados nesse estudo.

Nesse contexto, Hirose et al. ${ }^{9}$ observaram em ratos que tiveram a pata esquerda imobilizada em posição neutra durante 7 dias, redução na transdução do sinal intracelular estimulado pela insulina, sugerindo déficit na ativação do IR (receptor de insulina) e nas moléculas ativadas a partir deste, incluindo a fosforilação do IRS-1(substrato 1 do receptor de insulina) e a ativação da PI3-K (fosfatidilinositol 3-quinase), indicando que o quadro de resistência à insulina também pode ser desencadeado na imobilização.

Com relação à utilização da EE nesse trabalho, o recurso mostrou ser eficaz em minimizar o aumento da densidade de área do tecido conjuntivo, bem como a redução da área das fibras musculares do sóleo submetido à imobilização durante 15 dias. Esses resultados corroboram a afirmação de Avramidis et al. ${ }^{25}$ que descreveram a importância da EE com objetivos de recuperar a força muscular, reduzir a proliferação do tecido conjuntivo intramuscular, reduzir o tempo de reabilitação e prevenir a atrofiamuscular decorrente da imobilização.

Qin et al. ${ }^{11}$ utilizaram EE com freqüência de $50 \mathrm{~Hz}$ aplicada diariamente por 30 minutos, 5 vezes na semana durante 3 semanas no músculo tibial anterior de coelhos e observaram que o recurso foi efetivo na prevenção da atrofia muscular minimizando a redução da área de secção transversal, fibrose intersticial e deficiência de suprimento sanguíneo. Além disso,
Polacow et al. ${ }^{15}$ também demonstraram que a EE (f: $10 \mathrm{~Hz}$, $\mathrm{T}$ : $3 \mathrm{~ms}$, pulsos quadráticos bifásicos, On/Off de 2:2 segundos, 20 minutos) promoveu redução da densidade de área do tecido conjuntivo nos músculos sóleo desnervados por 15 dias, apontando para possível redução da fibrose, e aumento na quantidade de grânulos de glicogênio.

Cabe ressaltar, conforme tabela 1, que a EE também promoveu elevação nas reservas de glicogênio tanto nos músculos normais quanto nos imobilizados. Resultados semelhantes foram descritos por Guirro et al. ${ }^{16}$, que a EE promoveu aumento das reservas de glicogênio nos músculos da pata posterior de ratos submetidos à desnervação por um período de 30 dias.

O aumento no conteúdo de glicogênio observado nesse trabalho em todos os músculos imobilizados se deve à maior captação de glicose pela população de GLUT4, insensível à insulina, que são externalizados, e decorre, ainda, da ativação dos sistemas enzimáticos citosólicos na glicogênese ${ }^{26}$. Certamente, a EE promove elevação na atividade contrátil das fibras musculares, desse modo a dinâmica de captação e metabolismo da glicose e a atividade das vias metabólicas celulares são aumentadas ${ }^{14,16}$.

Neste sentido, Etgen et al. ${ }^{27}$ avaliaram o conteúdo de GLUT 4 no músculo plantar de ratos após EE crônica, e verificaram aumento de $82 \%$ em seu conteúdo. Períodos maiores de EE, 30 a 40 e 60 a 90 dias, mostraram somente tendência ao aumento no conteúdo do GLUT 4, atingindo um platô em torno de 30 a 40 dias. Um resultado importante do estudo de Hamada et al. ${ }^{28}$ foi que a captação de glicose corporal em ratos é agudamente aumentada em resposta a 20 minutos de EE e este aumento perdura por pelo menos 90 minutos após a finalização da utilização do recurso.

\section{CONCLUSÃO}

A estimulação elétrica neuromuscular minimizou a redução das reservas de glicogênio nos músculos da pata posterior submetidos à imobilização durante 15 dias. Também foi observado que o recurso preveniu a redução da área das fibras, bem como da proliferação do tecido conjuntivo no músculo sóleo. Vale ressaltar a importância da intervenção fisioterapêutica durante esse período, com objetivo de minimizar as alterações musculoesqueléticas inerentes ao desuso.

\section{REFERÊNCIAS BIBLIOGRÁFICAS}

1. Bodine SC, Latres E, Baumhueter S, Lai VKM, Nunez L, Clarke $\mathrm{BA}$, et al. Identification of Ubiquitin Ligases Required for Skeletal Muscle Atrophy. Science 2001; 23: 1704-1708.

2. Kannus P, Jozsa L, Jarvinen TL, Kvist M, Vieno T, Jarvinen TA, et al. Free mobilization and low- to high-intensity exercise in immobilization-induced muscle atrophy. J Appl Physiol. 1998; 84(4):1418-24. 
3. Gomes ARS, Coutinho EL, França CN, Polonio J, Salvini TF. Effect of one stretch a week applied to the immobilized soleus muscle on rat muscle fiber morphology. Braz J Med Biol Res 2004; 37: 1473-1480.

4. Amiel D, Woo SLY, Harwood FL, Akeson WH. The effect of immobilization on collagen turnover in connective tissue: a biochemical-biomechanical correlation. Acta orthop scan 1982; 53: 325-332.

5. Williams PE, Goldspink G. Connective tissue changes in immobilized muscle. J Anat 1984; 138: 343-504.

6. Okita M, Yoshimura T, Nakano J, Motomura M, Eguchi K. Effects of reduced joint mobility on sarcomere length, collagen fibril arrangement in the endomysium, and hyaluronan in rat muscle. J Muscle Res Cell Motil 2004; 25:159-66.

7. Ferrando AA, Lane HW, Stuart CA, Davis-Street J, Wolfe RR. Prolonged bed rest decreases skeletal muscle and whole body protein synthesis. Am J Physiol 1996; 270: 627-33.

8. Reardon KA, Davis J, Kapsa RM, Choong P, Byrne E. Myostatin, insulin-like growth factor-1, and leukemia inhibitory factor are upregulated in chronic human disuse muscle atrophy. Muscle Nerve 2001; 24(7):893-9.

9. Hirose M, Kaneki M, Sugita H, Yasuhara S, Martyn JA. Immobilization depresses insulin signaling in skeletal muscle. Am J Physiol Endocrinol Metab 2000; 279(6): 1235-41.

10. Durigan JLD, Cancelliero KM, Polacow, MLO, Silva CA, Guirro, RRJ. Modelos de desuso muscular e estimulação elétrica neuromuscular: aspectos pertinentes à reabilitação. Fisio Mov 2005; 18(4): 53-62.

11. Qin L, Appell HJ, Chan KM, Maffulli N. Electrical stimulation prevents immobilization atrophy in skeletal muscle of rabbits. Arch Phys Med Rehabil 1997: 78: 512-7.

12. Józsa L, Thoring J, Jarvinen M, Kannus P, Lehto M, Kvist M. Quantitative alterations in intramuscular connective tissue following immobilization: An experimental study in the rat calf muscles. Exp Mol Pathol 1988; 49: 267-278.

13. Picquet F, Falempin M. Compared effects of hindlimb unloading versus terrestrial deafferentation on muscular proprieties of the rat soleus. Exp Neurol 2003; 182: 186-94.

14. Silva CA, Guirro RRJ, Polacow MLO, Silva HC, Tanno AP, Rodrigues D. Efeito da meftormina e estimulação elétrica sobre as reservas de glicogênio do músculo sóleo normal e denervado. Rev Bras Fisiot 1999; 3: 55-60.

15. Polacow MLO, Silva CA, Guirro RRJ, Campos MR, Borges JP. Estudo morfométrico do músculo sóleo denervado de ratos tratados pela associação de metformina e estimulação elétrica. Rev Bras Fisioter 2003; 7: 77-84.
16. Guirro RRJ, Silva CA, Forti F, Cancelliero KM. Análise do musculoesquelético desnervado tratado com metformina e/ou estimulação elétrica de baixa freqüência. Rev Bras Fisioter 2004; 8: 21-27.

17. Silva CA, Guirro RRJ, Polacow MLO, Cancelliero KM, Durigan JLQ. Rat hindlimb joint immobilization with acrylic resin orthoses. Braz J Med Biol Res 2006; 39: 979-985.

18. Siu LO, Russeau JC, Taylor AW. Determination of glycogen in small tissue samples. J Apll Physiol 1970; 28: 234-236.

19. Mathieu O, Cruz-orive LM, Hoppeler H, Weibel ER. Measuring error and sampling variation in stereology: comparison of the efficiency of various methods for planar image analysis. J Microsc 1981; 121: 75-88.

20. Józsa L, Kannus P, Thoring J, Reffy A, Jarvinen M, Kvist M. The effect of tenotomy and immobilization on intramuscular connective tissue. J Bone Joint Surg 1990; 72: 293-7.

21. Heslinga HJ, Kronnie G, Huijing PA. Growth and immobilization effects on sarcomeres: a camparison between gastrocnemius and soleus muscles of the adult rat. Eur J Appl Physiol Occup Physiol 1995; 70: 49-57.

22. Appell HJ. Muscular atrophy following immobilization. Sports Med 1990; 7: 42-58.

23. Ploug T, Ohkuwa T, Handberg A, Vissing J, Galbo H. Effect of immobilization on glucose transport and glucose transporter expression in rat skeletal muscle. Am J Physiol 1995; 268: 980 986.

24. Lieber RL. Skeletal muscle structure, function, and plasticity, the physiological basis of rehabilitation. $2^{\text {nd }}$ ed. Philadelphia: Lippincott, 2002.

25. Avramidis K, Strike PW, Taylor PN, Swain ID. Effectiveness of electric stimulation of the vastus medialis muscle in the rehabilitation of patients after total knee arthroplasty. Arch Phys Med Rehabil 2003; 84: 1850-53.

26. Goodyear LJ, Hirshman MF, Valyou PM, Horton ES. Glucose transporter number, function, and subcellular distribution in rat skeletal muscle after exercise training. Diabetes 1992; 41: 10911099.

27. Etgen GJ, Farrar RP, Ivy JL. Effect of chronic electrical stimulation on GLUT 4 protein content in fast-twitch muscle. Am J Physiol 1993; 264: 816-19.

28. Hamada T, Sasaki H, Hayashi T, Moritani T, Nakao K. Enhancement of whole body glucose uptake during and after human skeletal muscle low-frequency electrical stimulation. J Appl Physiol 2003; 94: 2107-2112. 